\title{
A NEW MODEL FOR EVALUATING THE VOLUME OF LAPTOP SPARE PARTS DEPENDING ON USERS' INTENTIONS RELATED TO LAPTOP USE TIME
}

\author{
Lu, X. C. ${ }^{*} \&$ Hjelle, H. M.* \\ *School of Economics and Management, Beijing Jiaotong University, Beijing, China \\ ${ }^{* *}$ Molde University College, Molde, Norway \\ E-Mail: Xclu@bjtu.edu.cn, Haralld.Hjelle@himolde.no
}

\begin{abstract}
This paper is a continuing studying about the volume of laptop spare parts, and it takes into account the users' repair intentions. We found that when a laptop is no longer working, whether it will be repaired is determined by the user's intention. The user's intention is related to the number of times that his laptop fails and to its use time, i.e., how long the laptop has been used. Therefore, this paper focuses on the volume of laptop spare parts calculation equation. First, we assume the failure process of laptop parts is a Poisson process, and the failure probability of laptop spare parts can calculate at different times. We deduce the transition probability formula of users' repair intention related to laptop use time. Finally, the equation to calculate the volume of spare parts is presented in this paper and is verified by simulation. The simulation results agree with the theoretical values. From the simulation curve, we know that the volume of spare parts will decrease sharply when the laptop use time is long. After having used a laptop for five years, a user is less likely to have a broken laptop repaired. Therefore, laptop factories could reduce the inventories of spare parts.

(Received, processed and accepted by the Chinese Representative Office.)
\end{abstract}

Key Words: Laptop Spare Parts, Users' Repair Intention, Simulation

\section{INTRODUCTION}

For the industrial service system, although supply chain planning and corporate coordination can directly improve mass customization capability [1], manufactures must store a certain amount of spare parts in their warehouses for after-sale service. Some researchers think that an efficient method to manage spare parts in warehouses can minimize inventory and reduce machine downtime [2]. We believe the most important thing is to evaluate the repair demand for spare parts.

This paper focuses on spare parts for laptops, which are becoming something of a fashion item. When a laptop breaks, will the user have it repaired? The user might not fix the laptop if it is old. Therefore, should manufactures store many spare parts in their warehouses for repairing broken products?

We find that whether a user will have his broken laptop repaired is determined by his intentions, which include two factors: how many times the laptop has broken (its broken frequency) and its use time. We previously published a paper about laptop spare parts quantities in consideration of users' intentions, which considered the number of times the laptop has broken previously [3]. In this paper, we discuss another case: the users' intention influenced by how long ago the laptop was bought. This situation is more complex than the first paper.

\section{LITERATURE REVIEW}

Several researchers investigate the issues of spare parts [4-6]. Some researchers believe that the question of spare parts is an inventory issue. Howard et al. introduced an (S,T) policy to 
control an inventory system [7]. Through joint optimization of preventive maintenance and inventory policies, Jiang et al. optimized the perishable spare parts maximum inventory level and provided the uniqueness condition under the DDI model for multi-unit systems [8]. De Smidt-Destombes et al. developed a heuristics algorithm for the joint optimization of variables. Their approach balanced maintenance frequencies, the inventories of spare parts and repair capacity [9]. Liao and Rausch proposed a degradation limit maintenance policy, namely, a base-stock spare parts inventory control policy and a two-stage approach. In their paper, simulation was applied to calculate the optimal base-stock level and maintenance threshold [10].

The inventory control policy of spare parts is the focus of most investigations. Nosoohi and Hejazi proposed a suboptimal control policy to minimize the total cost and applied multiple HPP to balance the production of hybrid repair and remanufacturing systems [11]. Stefanovic combined the unified business intelligence semantic model with data mining technology to provide better policy for an inventory of spare parts [12]. Kontrec et al. observed the total unit times as a stochastic process, and he proposed a new approach to decrease the demand for a spare parts inventory [13]. Romeijnders et al. developed a two-step method for forecasting the demand for spare parts [14]. Zanjani and Nourelfath used deterministic and stochastic models to optimize the minimum inventory of spare parts [15].

Wang and Syntetos proposed an approach to forecast demand based on the generation process [16]. Bian et al. investigated the time-varying variation of non-stationary spares demand and created a function linking the dynamic demand for spare parts and time-varying tasks. The non-homogeneous Poisson distribution was applied in their paper to obtain a calculation model for backorders [17]. On the basis of deficiencies in the construction industry in the area of strategic management, Wagner and Lindemann proposed the foundation strategies of spare parts management, spare parts inventories and the outsourcing of supply chain processes [18].

With respect to spare parts provisioning, Sahba et al. analysed the hybrid priority model and hybrid FCFS model for spare parts supply issue and concluded that the hybrid priority policy is better if the minimum availability expected from each system is not close to the minimum availability of another system [19]. In multi-echelon, multi-indenture spare part networks, van der Heijden et al. optimized a heuristic model considering inventory control and throughput time reduction by balancing the cost between TPT reduction and spare part inventories [20]. Costantino et al. presented an innovative model, solved by marginal analysis to control the inventory of multi-echelon, multi-indenture spare parts. In this paper, the authors proposed that three different directions could be extended by this model [21].

Because of the diversity of spare parts, some researchers proposed different methods to forecast spare parts demand in various research fields. For critical spare parts, Trusevych et al. developed the CVaR (conditional value-at-risk) approach to optimize critical spare parts inventory levels [22]. Gu et al. programmed two non-linear models forecasting demand according to installed parts failure distribution to solve inventory problems. The aim of their models was to reduce the cost of downtime due to shortages [23]. Do Rego and de Mesquita utilized three models for forecasting spare parts demand. The authors first recorded demand and then applied six demand distributions to forecast and control the inventory of automotive spare parts [24].

For electrical spare parts, Vaitkus et al. applied both conventional methods (perplexed forecasting techniques) and an improved model selection method to forecast the demand for electric spare parts [25]. For electrical equipment, the consumption of spare parts is commonly assumed to be a Poisson process. Lengu et al. proposed an empirical distribution of spare parts by fitting of various compound Poisson distributions and studying a distribution-based demand classification solution [26]. 
For mechanical spare parts, the issue is different than for electrical spare parts. Barabadi et al. proposed an approach for spare parts supply using a reliability regression model with covariates via a case study of drill bits in Jajarm Bauxite Mine, Iran [27]. Chen et al. adopted a simulation-optimization method combined with an age-based preventive replacement, an inventory rationing policy and a scatter search to reduce the impact of machine breakdowns and the cost of equipment maintenance [28].

\section{THE LAPTOP SPARE PARTS MODEL CONSIDERING USERS' INTENTIONS RELATED TO USE TIME}

The lifetime of electric facilities is an exponential distribution, and the failure process can be described as a Poisson process [29]. Therefore, the failure process of laptops can be discussed using this theory.

\subsection{The failure process of laptops}

We assume that there are some new laptops and divide their lifetime into different stages $n$. We note $t_{j}$ as the time in stage $j,\left\{N\left(t_{j}\right), t_{j} \geq 0\right\}$ as the laptop failure process, and the parameter $\lambda$ $(\lambda>0)$ as the failure rate. The failure probability of a laptop in $\left(t_{j-1}, t_{j}\right]$ is:

$$
\begin{aligned}
& P\left\{t_{j-1}<S_{n} \leq t_{j}, N\left(t_{j}\right) \geq n\right\} \\
& =P\left\{S_{n} \leq t_{j}, N\left(t_{j}\right) \geq n\right\}-P\left\{S_{n} \leq t_{j-1}, N\left(t_{j-1}\right) \geq n\right\} \\
& =e^{-\lambda t_{j}} \cdot \sum_{k=0}^{n-1} \frac{\lambda^{k}}{k !}\left[e^{\lambda s}\left(t_{j-1}\right)^{k}-t_{j}{ }^{k}\right]
\end{aligned}
$$

In Eq. (1), $n$ is the laptop breakage time and $S_{n}$ is the duration. So, $S_{n}=s=t_{j}-t_{j-1}$ [30].

\subsection{The breakdown probability of a laptop with several parts}

As discussed in our first paper [3], we assume that Part1, Part2 and Part3 are 3 parts of a laptop. $\lambda_{1}, \lambda_{2}$, and $\lambda_{3}$ are their breakdown rates, respectively. We note their failure processes as $N_{1}(t), N_{2}(t)$, and $N_{3}(t)$, respectively. $N(t)=N_{1}(t)+N_{2}(t)+N_{3}(t)$ is a compound Poisson process. We denote $\lambda$ as the compound failure rate: $\Sigma \lambda=\lambda_{1}+\lambda_{2}+\lambda_{3}$.

We denote $P_{N_{1}}, P_{N_{2}}, P_{N_{3}}$ as the failure probabilities of these parts during $\left(t_{j-1}, t_{j}\right]$. They are described in Eq. (2).

$$
\left\{\begin{array}{l}
P_{N_{1}}\left\{t_{j-1}<S_{n} \leq t_{j}, N\left(t_{j}\right)=n\right\} \\
=\lambda_{1} e^{-\sum \lambda t_{j}} \cdot \sum_{k=0}^{n-1} \frac{\left(\sum \lambda\right)^{k-1}}{k !}\left[e^{\sum \lambda s}\left(t_{j-1}\right)^{k}-t_{j}^{k}\right] \\
P_{N_{2}}\left\{t_{j-1}<S_{n} \leq t_{j}, N\left(t_{j}\right)=n\right\} \\
=\lambda_{2} e^{-\sum \lambda t_{j}} \cdot \sum_{k=0}^{n-1} \frac{\left(\sum \lambda\right)^{k-1}}{k !}\left[e^{\sum \lambda s}\left(t_{j-1}\right)^{k}-t_{j}^{k}\right] \\
P_{N_{3}}\left\{t_{j-1}<S_{n} \leq t_{j}, N\left(t_{j}\right)=n\right\} \\
=\lambda_{3} e^{-\sum \lambda t_{j}} \cdot \sum_{k=0}^{n-1} \frac{\left(\sum \lambda\right)^{k-1}}{k !}\left[e^{\sum \lambda s}\left(t_{j-1}\right)^{k}-t_{j}^{k}\right] \\
\sum \lambda=\lambda_{1}+\lambda_{2}+\lambda_{3} \\
t_{j}-t_{j-1}=s
\end{array}\right.
$$




\subsection{The repair probability depending on users' intention related to laptop use time}

We consider the repair probability, which depends on a user's repair intention based on his laptop use time. We obtain online survey data of users' repair intentions (shown in Table I). In the first 3 months, all users have their laptops repaired without hesitation. However, from the $57^{\text {th }}$ month to the $60^{\text {th }}$ month, few users have their laptops repaired.

In Table I, we separate use time into 20 stages in 3 month intervals. The variable $j$ is the stage number. We denote $\delta_{j}$ as users' repair intentions in the $j^{\text {th }}$ stage and note the intention transition probability mean as $\Phi\left\{t_{j-1}<S_{n}<t_{j}, N(t)\right\}$ when the laptop failure frequency is $n$. The calculation of $\Phi$ is more complex. Fig. 2 shows a chart of the transition probability path.

Table I: The Repair intention related to use time.

\begin{tabular}{|c|c|c|c|}
\hline Stage $\boldsymbol{j}$ & Use time (months) $\boldsymbol{t}_{\boldsymbol{j}}$ & Repair intention & $\boldsymbol{\delta}_{\boldsymbol{j}}$ \\
\hline 1 & 3 & $100 \%$ & $\delta_{1}$ \\
\hline 2 & 6 & $93 \%$ & $\delta_{2}$ \\
\hline 3 & 9 & $86 \%$ & $\delta_{3}$ \\
\hline 4 & 12 & $79 \%$ & $\delta_{4}$ \\
\hline 5 & 15 & $63 \%$ & $\delta_{5}$ \\
\hline 6 & 18 & $57 \%$ & $\delta_{6}$ \\
\hline 7 & 21 & $52 \%$ & $\delta_{7}$ \\
\hline 8 & 24 & $48 \%$ & $\delta_{8}$ \\
\hline 9 & 27 & $36 \%$ & $\delta_{9}$ \\
\hline 10 & 30 & $35 \%$ & $\delta_{10}$ \\
\hline 11 & 33 & $32 \%$ & $\delta_{11}$ \\
\hline 12 & 36 & $22 \%$ & $\delta_{12}$ \\
\hline 13 & 39 & $21 \%$ & $\delta_{13}$ \\
\hline 14 & 42 & $19 \%$ & $\delta_{14}$ \\
\hline 15 & 45 & $18 \%$ & $\delta_{15}$ \\
\hline 16 & 48 & $13 \%$ & $\delta_{16}$ \\
\hline 17 & 51 & $12 \%$ & $\delta_{17}$ \\
\hline 18 & 54 & $11 \%$ & $\delta_{18}$ \\
\hline 19 & 57 & $10 \%$ & $\delta_{19}$ \\
\hline 20 & 60 & $4 \%$ & $\delta_{20}$ \\
\hline
\end{tabular}

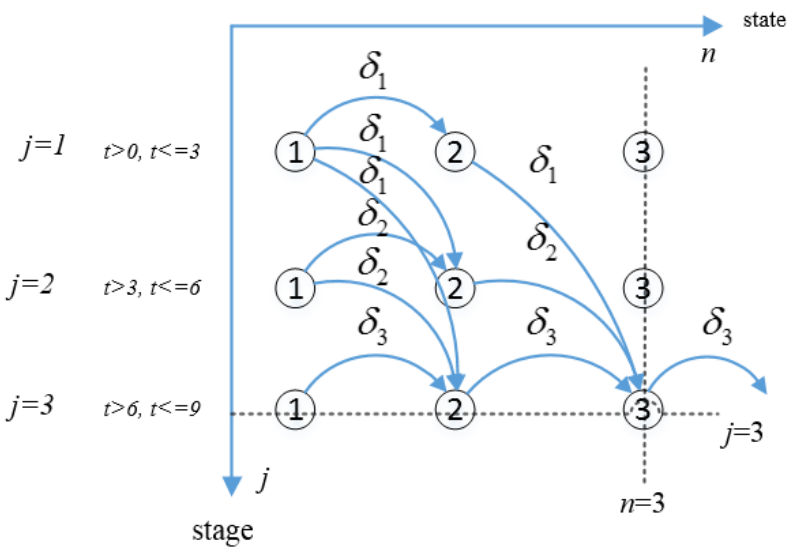

Figure 1: The path of the transition probability of the user's repair intention related to use time (use time $t_{j}=9$ months, state $n=3$, stage $j=3$ ). 
We provide an example to show the complexity of calculating the transition probability mean. Eq. (3) is the formula for the users' repair intention transition probability calculation in Fig. 1. There is no regular pattern in Eq. (3).

$$
\begin{aligned}
\Phi\left\{6<S_{3} \leq 9, N(t)\right\} & =\frac{1}{6}\left(\delta_{1} \delta_{1}+\delta_{2} \delta_{2}+\delta_{3} \delta_{3}+\delta_{1} \delta_{2}+\delta_{2} \delta_{3}+\delta_{1} \delta_{3}\right) \delta_{3} \\
& =\frac{1}{6}\left(\delta_{1}^{2}+\delta_{2}^{2}+\delta_{3}^{2}+\delta_{1} \delta_{2}+\delta_{2} \delta_{3}+\delta_{1} \delta_{3}\right) \delta_{3}
\end{aligned}
$$

To deduce the formula of the repair intention transition probability, we provide a recurrence derivation.

We note $X(j, n)$ as the sum of the repair intention transition probability in which $n$ represents a laptop's number of failures and $j$ represents its stage of use time (stage $j$ is listed in Table I).

We denote $M(j, n)$ as the number of transition paths. Therefore, $\Phi\left\{t_{j-1}<S_{n}<t_{j}, N(t)\right\}$ can be written as:

$$
\Phi\left\{t_{j-1}<S_{n}<t_{j}, N(t)\right\}=\frac{X(j, n)}{M(j, n)}
$$

When a laptop breaks for the first time $(n=1), X(j, 1)$ and $M(j, 1)$ can be written as:

$$
\begin{gathered}
\left\{\begin{array}{l}
X(j, 1)=\delta_{j} \\
M(j, 1)=1
\end{array}\right. \\
\left\{\begin{array}{l}
\Phi\left\{t_{j-1}<S_{n}<t_{j}, N(t)\right\}=\frac{X(j, n)}{M(j, n)} \\
X(j, n)=\delta_{j} \sum_{k=1}^{j} X(k, n-1) \\
M(j, n)=\sum_{k=1}^{j} M(k, n-1) \\
n \geq 2, j \in[1,20]
\end{array}\right.
\end{gathered}
$$

In Eq. (5), $\delta_{j}$ is the repair intention probability, which is shown in Table I.

When a laptop has been broken $n$ times, and it is in the $j^{\text {th }}$ stage, the transition probability path is shown as Fig. 2. $X(j, n)$ and $M(j, n)$ can be written as Eq. (6). In Table I, the stage is separated into 20 sections, so $j$ is not more than 20 in Eq. (6).

Using Eqs. (2), (4), (5) and (6), the breakdown probability can be deduced.

For Part 1, when it is at stage $j$, and the number of failures is $n$, the probability of its being sent to repair is $\Phi(.) P_{N 1}($.$) . That is:$

$$
\begin{aligned}
P_{1}\left\{t_{j-1}<S_{n} \leq t_{j}, N\left(t_{j}\right)=n\right\}= & \Phi\left\{t_{j-1}<S_{n} \leq t_{j}, N\left(t_{j}\right)=n\right\} \cdot P_{N_{1}}\left\{t_{j-1}<S_{n} \leq t_{j}, N\left(t_{j}\right)=n\right\} \\
& =\lambda_{1} \frac{X(j, n)}{M(j, n)} e^{-\sum \lambda t_{j}} \cdot \sum_{k=0}^{n-1} \frac{\left(\sum \lambda\right)^{k-1}}{k !}\left[e^{\sum \lambda s}\left(t_{j-1}\right)^{k}-t_{j}^{k}\right]
\end{aligned}
$$

Let:

$$
Y(j, n)=\frac{X(j, n)}{M(j, n)} e^{-\sum \lambda t_{j}} \cdot \sum_{k=0}^{n-1} \frac{\left(\sum \lambda\right)^{k-1}}{k !}\left[e^{\sum \lambda s}\left(t_{j-1}\right)^{k}-t_{j}{ }^{k}\right]
$$

Hence:

$$
P_{1}\left\{t_{j-1}<S_{n} \leq t_{j}, N\left(t_{j}\right)=n\right\}=\lambda_{1} Y(j, n)
$$


Therefore, the probability that the laptop parts will be sent for repair can be calculated by Eq. (7).

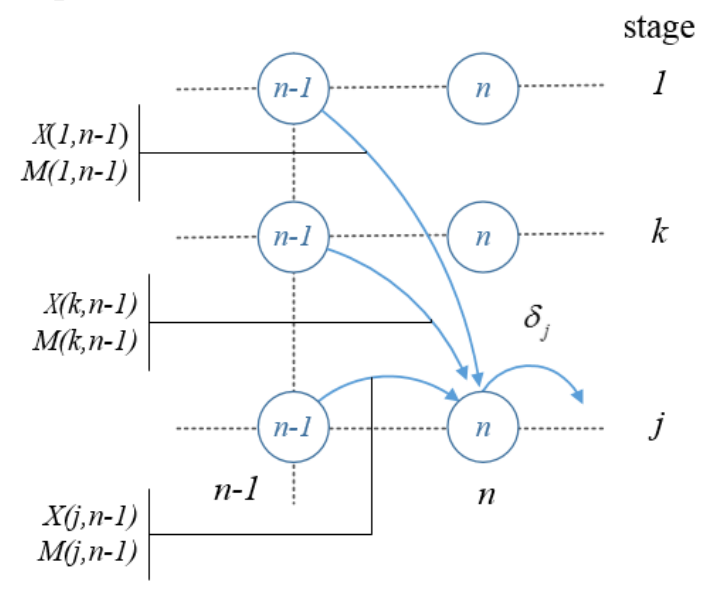

Figure 2: The repair intention transition probability path.

Now, we obtain a formula for the laptop repair probability. Eq. (2) is the repairing probability related to failure frequency. Eq. (7) is the repairing probability related to laptop use time.

$$
\left\{\begin{array}{l}
P_{1}\left\{t_{j-1}<S_{n} \leq t_{j}, N\left(t_{j}\right)=n\right\}=\lambda_{1} Y(j, n) \\
P_{2}\left\{t_{j-1}<S_{n} \leq t_{j}, N\left(t_{j}\right)=n\right\}=\lambda_{2} Y(j, n) \\
P_{3}\left\{t_{j-1}<S_{n} \leq t_{j}, N\left(t_{j}\right)=n\right\}=\lambda_{3} Y(j, n) \\
\sum \lambda=\lambda_{1}+\lambda_{2}+\lambda_{3} \\
Y(j, n)=\frac{X(j, n)}{M(j, n)} e^{-\sum \lambda t_{j}} \cdot \sum_{k=0}^{n-1} \frac{\left(\sum \lambda\right)^{k-1}}{k !}\left[e^{\sum \lambda s}\left(t_{j-1}\right)^{k}-t_{j}{ }^{k}\right] \\
X(j, n)=\delta_{j} \sum_{k=1}^{j} X(k, n-1), M(j, n) \\
\quad=\sum_{k=1}^{j} M(k, n-1) \\
X(j, 1)=\delta_{j}, M(j, 1)=1, n \geq 2, j \in(1,20)
\end{array}\right.
$$

We denote the volume of laptops as $V$, the volume of Part1 as $V_{1}$, the volume of Part2 as $V_{2}$, and the volume of Part3 as $V_{3}$. Using Eq. (7), we can determine the volume of spare parts with Eq. (8).

$$
\left\{\begin{array}{l}
V_{1}=V \lambda_{1} \sum_{j} \sum_{n} Y(j, n) \\
V_{2}=V \lambda_{2} \sum_{j} \sum_{n} Y(j, n) \\
V_{3}=V \lambda_{3} \sum_{j} \sum_{n} Y(j, n)
\end{array}\right.
$$

\section{MODELLING VERIFICATION}

We verify Eq. (7) in this section. Because Eq. (8) is deduced from Eq. (7), it does not require verification. 
We assume that there are 1000 new laptops and that there are 3 parts in a laptop. The failure rates of these parts are as follows: $\lambda_{1}=0.025$ per month, $\lambda_{2}=0.020$ per month, and $\lambda_{3}=0.0167$ per month.

\subsection{The repair probability of spare parts verification}

A simulation model is programmed to verify Eq. (7). The process chart of the simulation program is shown as Fig. 3. In this program, when a part is broken, a user will decide whether to send his laptop for repair. In Fig. 3, this decision depends on the value of the stochastic variable $\delta$, which represents the repair intention found in Table I.

According to Eq. (7), $X(j, n)$ and $M(j, n)$ can be determined, and the calculation results are shown in Table II and Table III. Finally, $Y(j, n)$ is calculated. The repair probability of Part1, considering the user's repair intention related to laptop use time, is shown in Table IV. In Table IV, when $j=10, n=3, s=3$, and we can obtain $P_{1}\left\{27<S_{n} \leq 30, N(30)=3\right\}=0.00296$. For every 1000 laptops, there will be approximately 3 pcs of Part1 spare parts that should be prepared for after-sale service. The repair probability of Part2 and Part3 can be calculated in the same way.

Table II: The probability of $X(j, n)$.

\begin{tabular}{|c|c|c|c|c|c|c|c|}
\hline Laptop use time & \multicolumn{7}{|c|}{ Failure times $\boldsymbol{7}$} \\
\hline Stage $\boldsymbol{j}$ & $\mathbf{1}$ & $\mathbf{2}$ & $\mathbf{3}$ & $\mathbf{4}$ & $\mathbf{5}$ & $\mathbf{6}$ & $\mathbf{7}$ \\
\hline 1 & 1 & 1 & 1 & 1 & 1 & 1 & 1 \\
\hline 2 & 0.93 & 1.80 & 2.62 & 3.37 & 4.08 & 4.74 & 5.36 \\
\hline 3 & 0.86 & 2.41 & 4.50 & 6.99 & 9.80 & 12.83 & 16.01 \\
\hline 4 & 0.79 & 2.84 & 6.37 & 11.46 & 18.06 & 26.07 & 35.33 \\
\hline 5 & 0.63 & 2.68 & 6.80 & 13.49 & 23.02 & 35.48 & 50.79 \\
\hline 6 & 0.57 & 2.76 & 7.75 & 16.69 & 30.47 & 49.69 & 74.62 \\
\hline 7 & 0.52 & 2.78 & 8.52 & 19.66 & 38.05 & 65.18 & 102.10 \\
\hline 8 & 0.48 & 2.79 & 9.15 & 22.43 & 45.68 & 81.73 & 132.91 \\
\hline 9 & 0.36 & 2.21 & 7.62 & 19.46 & 41.05 & 75.68 & 126.27 \\
\hline 10 & 0.35 & 2.25 & 8.15 & 21.65 & 47.20 & 89.54 & 153.13 \\
\hline 11 & 0.32 & 2.18 & 8.19 & 22.53 & 50.62 & 98.55 & 172.36 \\
\hline 12 & 0.32 & 2.25 & 8.80 & 25.03 & 57.89 & 115.58 & 206.67 \\
\hline 13 & 0.22 & 1.59 & 6.39 & 18.59 & 43.81 & 88.92 & 161.29 \\
\hline 14 & 0.21 & 1.61 & 6.62 & 19.66 & 47.20 & 97.36 & 179.09 \\
\hline 15 & 0.19 & 1.47 & 6.16 & 18.64 & 45.49 & 95.15 & 177.19 \\
\hline 16 & 0.19 & 1.47 & 6.30 & 19.41 & 48.11 & 102.04 & 192.32 \\
\hline 17 & 0.13 & 1.05 & 4.56 & 14.22 & 35.63 & 76.27 & 144.94 \\
\hline 18 & 0.12 & 0.97 & 4.26 & 13.44 & 33.98 & 73.36 & 140.44 \\
\hline 19 & 0.11 & 0.88 & 3.93 & 12.51 & 31.92 & 69.42 & 133.79 \\
\hline 20 & 0.10 & 0.83 & 3.72 & 11.95 & 30.72 & 67.29 & 130.47 \\
\hline 21 & 0.04 & 0.37 & 1.65 & 5.33 & 13.75 & 30.20 & 58.72 \\
\hline 22 & 0 & 0 & 0 & 0 & 0 & 0 & 0 \\
\hline & & & & & & & \\
\hline
\end{tabular}




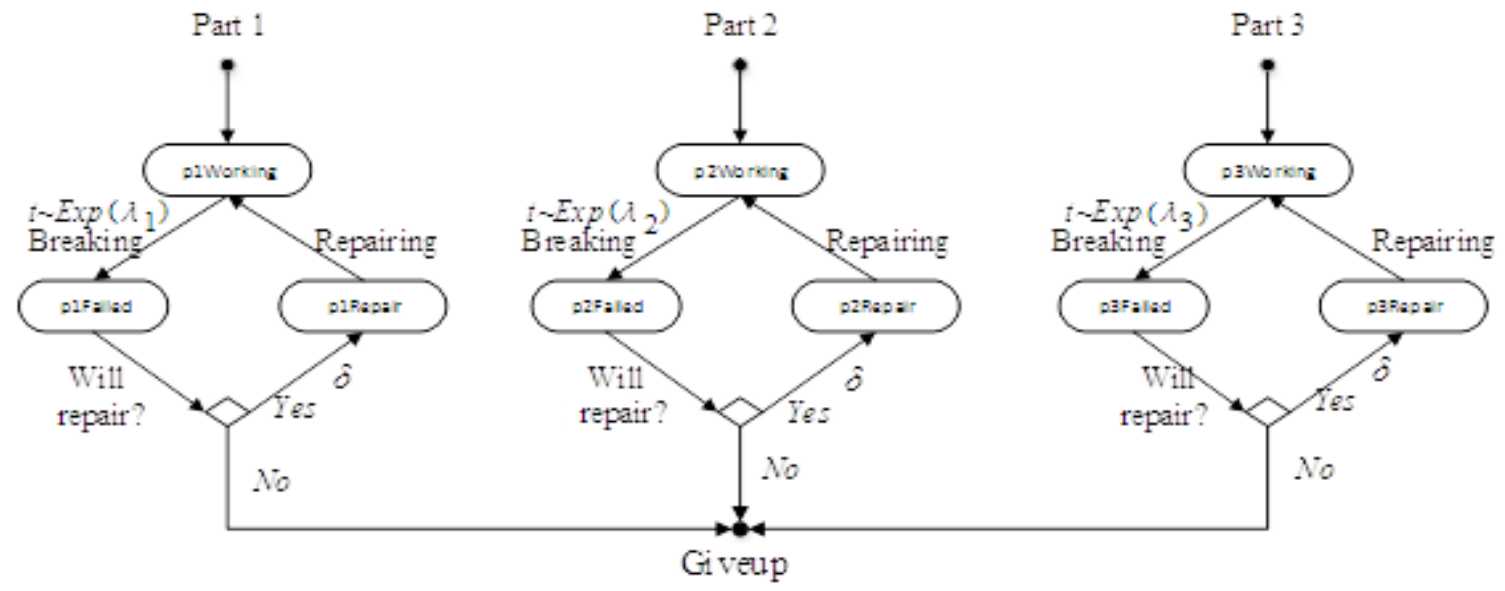

Figure 3: The simulation model of laptop broken parts and the repair process.

Table III: The $M(j, n)$ value.

\begin{tabular}{|c|c|c|c|c|c|c|c|}
\hline \multirow{2}{*}{ Stages $\boldsymbol{j}$} & \multicolumn{7}{|c|}{ Failure times $\boldsymbol{5}$} \\
\cline { 2 - 8 } & $\mathbf{1}$ & $\mathbf{2}$ & $\mathbf{3}$ & $\mathbf{4}$ & $\mathbf{5}$ & $\mathbf{6}$ & $\mathbf{7}$ \\
\hline 1 & 1 & 1 & 1 & 1 & 1 & 1 & 1 \\
\hline 2 & 1 & 2 & 3 & 4 & 5 & 6 & 7 \\
\hline 3 & 1 & 3 & 6 & 10 & 15 & 21 & 28 \\
\hline 4 & 1 & 4 & 10 & 20 & 35 & 56 & 84 \\
\hline 5 & 1 & 5 & 15 & 35 & 70 & 126 & 210 \\
\hline 6 & 1 & 6 & 21 & 56 & 126 & 252 & 462 \\
\hline 7 & 1 & 7 & 28 & 84 & 210 & 462 & 924 \\
\hline 8 & 1 & 8 & 36 & 120 & 330 & 792 & 1716 \\
\hline 9 & 1 & 9 & 45 & 165 & 495 & 1287 & 3003 \\
\hline 10 & 1 & 10 & 55 & 220 & 715 & 2002 & 5005 \\
\hline 11 & 1 & 11 & 66 & 286 & 1001 & 3003 & 8008 \\
\hline 12 & 1 & 12 & 78 & 364 & 1365 & 4368 & 12376 \\
\hline 13 & 1 & 13 & 91 & 455 & 1820 & 6188 & 18564 \\
\hline 14 & 1 & 14 & 105 & 560 & 2380 & 8568 & 27132 \\
\hline 15 & 1 & 15 & 120 & 680 & 3060 & 11628 & 38760 \\
\hline 16 & 1 & 16 & 136 & 816 & 3876 & 15504 & 54264 \\
\hline 17 & 1 & 17 & 153 & 969 & 4845 & 20349 & 74613 \\
\hline 18 & 1 & 18 & 171 & 1140 & 5985 & 26334 & 100947 \\
\hline 19 & 1 & 19 & 190 & 1330 & 7315 & 33649 & 134596 \\
\hline 20 & 1 & 20 & 210 & 1540 & 8855 & 42504 & 177100 \\
\hline 21 & 1 & 21 & 231 & 1771 & 10626 & 53130 & 230230 \\
\hline 22 & 1 & 22 & 253 & 2024 & 12650 & 65780 & 296010 \\
\hline
\end{tabular}

We have run a simulation model for 100 trials to verify Table IV and Eq. (7). The significance tests of the simulation data are shown in Table $\mathrm{V}$ and Table VI. Table V is the significance test when the failure frequency is $n=3$. Table VI is the significance test result when the number of failures is $n=1 \sim 7$.

Table V and Table VI show that all $p$ values are greater than 0.05 , and the simulation data fit the calculation data. Therefore, Eq. (7) is valid. 
From Fig. 4, we can see that users will not have their broken laptops fixed after having used them for 60 months.

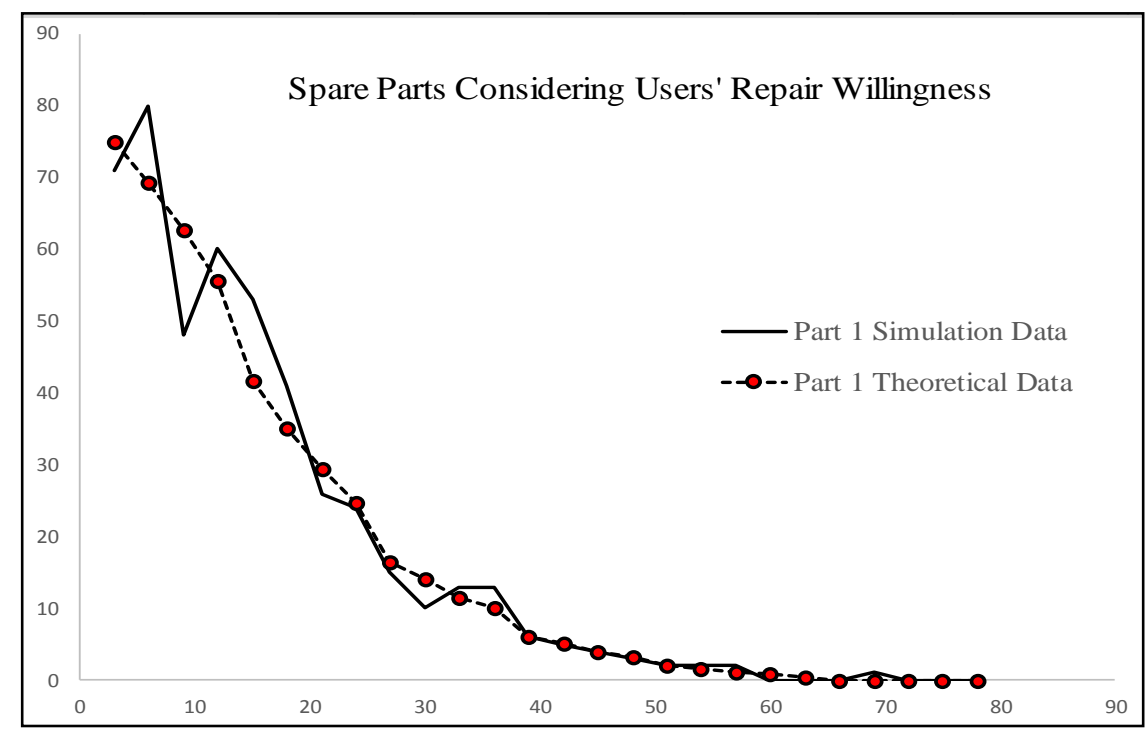

Figure 4: The simulation curve and theoretical curve of Part1 considering repair intentions $(n=1 \sim 7)$.

Table IV: The repair probability of Part1 considering repair intentions.

\begin{tabular}{|c|c|c|c|c|c|c|c|c|c|}
\hline \multirow{2}{*}{$\begin{array}{c}\text { Time } \boldsymbol{t} \text { (month) } \\
\text { Stages }\end{array}$} & $\boldsymbol{j}$ & $\mathbf{1}$ & $\mathbf{2}$ & $\mathbf{3}$ & $\mathbf{4}$ & $\mathbf{5}$ & $\mathbf{6}$ & $\mathbf{7}$ & \multirow{2}{*}{ sum } \\
\cline { 3 - 8 } & 1 & 0.06847 & 0.00614 & 0.00037 & 0.00002 & 0.00000 & 0.00000 & 0.00000 & 0.07500 \\
\hline 3 & 2 & 0.05310 & 0.01410 & 0.00194 & 0.00018 & 0.00001 & 0.00000 & 0.00000 & 0.06934 \\
\hline 6 & 3 & 0.04078 & 0.01746 & 0.00379 & 0.00056 & 0.00006 & 0.00001 & 0.00000 & 0.06266 \\
\hline 9 & 4 & 0.03110 & 0.01798 & 0.00524 & 0.00103 & 0.00015 & 0.00002 & 0.00000 & 0.05552 \\
\hline 12 & 5 & 0.02071 & 0.01450 & 0.00512 & 0.00121 & 0.00022 & 0.00003 & 0.00000 & 0.04180 \\
\hline 15 & 6 & 0.01561 & 0.01266 & 0.00517 & 0.00142 & 0.00029 & 0.00005 & 0.00001 & 0.03521 \\
\hline 18 & 7 & 0.01182 & 0.01077 & 0.00495 & 0.00153 & 0.00036 & 0.00007 & 0.00001 & 0.02950 \\
\hline 21 & 8 & 0.00901 & 0.00904 & 0.00458 & 0.00156 & 0.00040 & 0.00008 & 0.00001 & 0.02468 \\
\hline 24 & 9 & 0.00558 & 0.00600 & 0.00325 & 0.00119 & 0.00033 & 0.00007 & 0.00001 & 0.01644 \\
\hline 27 & 10 & 0.00449 & 0.00512 & 0.00296 & 0.00115 & 0.00034 & 0.00008 & 0.00002 & 0.01416 \\
\hline 30 & 11 & 0.00343 & 0.00413 & 0.00252 & 0.00103 & 0.00032 & 0.00008 & 0.00002 & 0.01154 \\
\hline 33 & 12 & 0.00282 & 0.00356 & 0.00228 & 0.00099 & 0.00032 & 0.00009 & 0.00002 & 0.01007 \\
\hline 36 & 13 & 0.00161 & 0.00210 & 0.00139 & 0.00062 & 0.00021 & 0.00006 & 0.00001 & 0.00602 \\
\hline 39 & 14 & 0.00131 & 0.00177 & 0.00121 & 0.00056 & 0.00020 & 0.00006 & 0.00001 & 0.00513 \\
\hline 42 & 15 & 0.00097 & 0.00135 & 0.00095 & 0.00045 & 0.00016 & 0.00005 & 0.00001 & 0.00394 \\
\hline 45 & 16 & 0.00079 & 0.00112 & 0.00081 & 0.00040 & 0.00015 & 0.00005 & 0.00001 & 0.00333 \\
\hline 48 & 17 & 0.00046 & 0.00067 & 0.00049 & 0.00025 & 0.00009 & 0.00003 & 0.00001 & 0.00200 \\
\hline 51 & 18 & 0.00035 & 0.00051 & 0.00038 & 0.00020 & 0.00008 & 0.00002 & 0.00001 & 0.00155 \\
\hline 54 & 19 & 0.00026 & 0.00039 & 0.00030 & 0.00015 & 0.00006 & 0.00002 & 0.00001 & 0.00119 \\
\hline 57 & 20 & 0.00020 & 0.00030 & 0.00023 & 0.00012 & 0.00005 & 0.00002 & 0.00000 & 0.00093 \\
\hline 60 & 21 & 0.00007 & 0.00011 & 0.00009 & 0.00005 & 0.00002 & 0.00001 & 0.00000 & 0.00035 \\
\hline 63 & 22 & 0.00000 & 0.00000 & 0.00000 & 0.00000 & 0.00000 & 0.00000 & 0.00000 & 0.00000 \\
\hline 66 & & & & & &
\end{tabular}


Table V: The simulation significance test ${ }^{*}$.

\begin{tabular}{|l|c|c|c|}
\hline \multicolumn{1}{|c|}{ Statics } & Part1 & Part2 & Part3 \\
\hline Simulation mean & 3.12 & 2.64 & 2.05 \\
\hline Standard deviation & 1.61 & 1.851 & 1.351 \\
\hline Mean confidence & 0.319 & 0.367 & 0.268 \\
\hline Theoretical mean & $2.96^{* *}$ & 2.37 & 1.97 \\
\hline$d f$ & 100 & 100 & 100 \\
\hline$t$ value & 1.01 & 1.48 & 0.58 \\
\hline Sig $(95 \%, 2$ tail $)$ & 0.3133 & 0.1412 & 0.5611 \\
\hline
\end{tabular}

${ }^{*}$ Laptops $=1000$ pcs, $30 \geq t>27$, stages $j=10$, failure times $n=3$, simulation trials $=100$.

${ }^{* *}$ Data are from Table IV.

Table VI: The simulation significance test considering all broken times.

\begin{tabular}{|l|c|c|c|}
\hline \multicolumn{1}{|c|}{ Statics } & Part1 & Part2 & Part3 \\
\hline Simulation Mean & 14.42 & 12.02 & 9.22 \\
\hline Standard deviation & 3.41 & 3.67 & 2.96 \\
\hline Mean confidence & 0.68 & 0.73 & 0.59 \\
\hline Theoretical mean & $14.16^{* *}$ & 11.32 & 9.44 \\
\hline$d f$ & 100 & 100 & 1000 \\
\hline$t$ value & 0.72 & 1.90 & 0.73 \\
\hline Sig $(95 \%, 2$ tail $)$ & 0.4757 & 0.0609 & 0.4645 \\
\hline
\end{tabular}

* Laptops $=1000$ pcs, $30 \geq t>27$, stages $j=10$, failure times $n=1 \sim 7$, simulation trials $=100$.

** Data are from Table IV.

Table VII: The spare parts volume in the warehouse at different times.

\begin{tabular}{|c|c|c|c|c|}
\hline Stage $\boldsymbol{j}$ & Month & Part1 & Part2 & Part3 \\
\hline 1 & 3 & 75 & 60 & 50 \\
\hline 2 & 6 & 69 & 55 & 46 \\
\hline 3 & 9 & 63 & 50 & 42 \\
\hline 4 & 12 & 56 & 44 & 37 \\
\hline 5 & 15 & 42 & 33 & 28 \\
\hline 6 & 18 & 35 & 28 & 23 \\
\hline 7 & 21 & 29 & 24 & 20 \\
\hline 8 & 24 & 25 & 20 & 16 \\
\hline 9 & 27 & 16 & 13 & 11 \\
\hline 10 & 30 & 14 & 11 & 9 \\
\hline 11 & 33 & 12 & 9 & 8 \\
\hline 12 & 36 & 10 & 8 & 7 \\
\hline 13 & 39 & 6 & 5 & 4 \\
\hline 14 & 42 & 5 & 4 & 3 \\
\hline 15 & 45 & 4 & 3 & 3 \\
\hline 16 & 48 & 3 & 3 & 2 \\
\hline 17 & 51 & 2 & 2 & 1 \\
\hline 18 & 54 & 2 & 1 & 1 \\
\hline 19 & 57 & 1 & 1 & 1 \\
\hline 20 & 60 & 1 & 1 & 1 \\
\hline & Total & 470 & 376 & 313 \\
\hline
\end{tabular}


From Table VII, we can see that the volume of Part1 $V_{1}$ is approximately 470 pcs, $V_{2}$ is approximately $376 \mathrm{pcs}$, and $V_{3}$ is approximately 313 pcs.

\section{CONCLUSION}

Using Eqs. (7) and (8), we can calculate the quantity of laptop spare parts that should be in stock for a laptop manufacturer. Table VII gives the spare parts volume for three parts. If the laptop manufacturer wants to meet $90 \%$ of the demand, he only needs to consider the first 30 months of repair demand. When a user has been using a laptop for 5 years (60 months), the user will rarely repair the broken laptop. Therefore, laptop factories could reduce their inventory. For example, in this paper, the spare parts inventory of Part1 is 1000 pcs if we do not consider the users' repair intentions. However, only 470 pcs are needed when considering repair intentions. This conclusion could help laptop manufactures to reduce spare parts inventories.

\section{ACKNOWLEDGEMENT}

This paper was funded by the National Natural Science Foundation of China (Grant No. 71390334), the Beijing Planning Office of Philosophy and the Social Science Research Project (14JDJGB034), and the EC-China Research Network on Integrated Container Supply Chain Project (No. 612546).

\section{REFERENCES}

[1] Yinan, Q.; Tang, M.; Zhang, M. (2014). Mass customization in flat organization: The mediating role of supply chain planning and corporation coordination, Journal of Applied Research and Technology, Vol. 12, No. 2, 171-181, doi:10.1016/S1665-6423(14)72333-8

[2] Duran, O. (2015). Spare parts criticality analysis using a fuzzy AHP approach, Technical Gazette, Vol. 22, No. 4, 899-905, doi:10.17559/TV-20140507002318

[3] Lu, X.-C.; Wang, H.-N. (2015). The laptop spare parts studying under considering users' repair willingness, International Journal of Simulation Modelling, Vol. 14, No. 1, 158-169, doi:10.2507/ijsimm14(1)co4

[4] Kareem, B.; Lawal, A. S. (2015). Spare parts failure prediction of an automobile under criticality condition, Engineering Failure Analysis, Vol. 56, 69-79, doi:10.1016/j.engfailanal.2015.04.011

[5] Conceicao, S. V.; Caetano, G. L.; Lu, D.-W.; Ramos Nunes, N. T.; Pedrosa, G. C. (2015). A demand classification scheme for spare part inventory model subject to stochastic demand and lead time, Production Planning \& Control, Vol. 26, No. 16, 1318-1331, doi:10.1080/ 09537287.2015.1033497

[6] Louit, D.; Pascual, R.; Banjevic, D.; Jardine, A. K. S. (2011). Optimization models for critical spare parts inventories - a reliability approach, Journal of the Operational Research Society, Vol. 62, No. 6, 992-1004, doi:10.1057/jors.2010.49

[7] Howard, C.; Marklund, J.; Tan, T.; Reijnen, I. (2015). Inventory control in a spare parts distribution system with emergency stocks and pipeline information, M\&SOM - Manufacturing \& Service Operations Management, Vol. 17, No. 2, 142-156, doi:10.1287/msom.2014.0508

[8] Jiang, Y.-P.; Chen, M.-Y.; Zhou, D.-H. (2015). Joint optimization of preventive maintenance and inventory policies for multi-unit systems subject to deteriorating spare part inventory, Journal of Manufacturing Systems, Vol. 35, 191-205, doi:10.1016/j.jmsy.2015.01.002

[9] De Smidt-Destombes, K. S.; van der Heijden, M. C.; van Harten, A. (2009). Joint optimisation of spare part inventory, maintenance frequency and repair capacity for $k$-out-of- $N$ systems, International Journal of Production Economics, Vol. 118, No. 1, 260-268, doi:10.1016/ j.ijpe.2008.08.058

[10] Liao, H.; Rausch, M. (2010). Spare part inventory control driven by condition based maintenance, Proceedings of the 2010 Annual Reliability and Maintainability Symposium, 6 pages, doi:10.1109/RAMS.2010.5448059 
[11] Nosoohi, I.; Hejazi, S. R. (2011). A multi-objective approach to simultaneous determination of spare part numbers and preventive replacement times, Applied Mathematical Modelling, Vol. 35, No. 3, 1157-1166, doi:10.1016/j.apm.2010.08.003

[12] Stefanovic, N. (2015). Collaborative predictive business intelligence model for spare parts inventory replenishment, Computer Science and Information Systems, Vol. 12, No. 3, 911-930, doi: 10.2298/csis141101034s

[13] Kontrec, N. Z.; Milovanović, G. V.; Panić, S. R.; Milošević, H. (2015). A reliability-based approach to nonrepairable spare part forecasting in aircraft maintenance system, Mathematical Problems in Engineering, Vol. 2015, Paper 731437, 7 pages, doi:10.1155/2015/731437

[14] Romeijnders, W.; Teunter, R.; van Jaarsveld, W. (2012). A two-step method for forecasting spare parts demand using information on component repairs, European Journal of Operational Research, Vol. 220, No. 2, 386-393, doi:10.1016/j.ejor.2012.01.019

[15] Zanjani, M. K.; Nourelfath, M. (2014). Integrated spare parts logistics and operations planning for maintenance service providers, International Journal of Production Economics, Vol. 158, 44-53, doi:10.1016/j.ijpe.2014.07.012

[16] Wang, W.-B.; Syntetos, A. A. (2011). Spare parts demand: Linking forecasting to equipment maintenance, Transportation Research Part E: Logistics and Transportation Review, Vol. 47, No. 6, 1194-1209, doi:10.1016/j.tre.2011.04.008

[17] Bian, J; Guo, L; Yang, Y.; Wang, N.-C. (2013). Optimizing spare parts inventory for time-varying task, Chemical Engineering Transactions, Vol. 33, 637-642, doi:10.3303/ CET1333107

[18] Wagner, S. M.; Lindemann, E. (2008). A case study-based analysis of spare parts management in the engineering industry, Production Planning and Control, Vol. 19, No. 4, 397-407, doi: 10.1080/09537280802034554

[19] Sahba, P.; Balcioglu, B.; Banjevic, D. (2013). Spare parts provisioning for multiple $k$-out-of- $n: G$ systems, IIE Transactions, Vol. 45, No. 9, 953-963, doi:10.1080/0740817x.2012.695102

[20] Van der Heijden, M. C.; Alvarez, E. M.; Schutten, J. M. J. (2013). Inventory reduction in spare part networks by selective throughput time reduction, International Journal of Production Economics, Vol. 143, No. 2, 509-517, doi:10.1016/j.ijpe.2012.03.020

[21] Costantino, F.; Di Gravio, G.; Tronci, M. (2013). Multi-echelon, multi-indenture spare parts inventory control subject to system availability and budget constraints, Reliability Engineering \& System Safety, Vol. 119, 95-101, doi:10.1016/j.ress.2013.05.006

[22] Trusevych, S. A.; Kwon, R. H.; Jardine, A. K. S. (2014). Optimizing critical spare parts and location based on the conditional value-at-risk criterion, Engineering Economist, Vol. 59, No. 2, 116-135, doi:10.1080/0013791x.2013.876795

[23] Gu, J.; Zhang, G.; Li, K. W. (2015). Efficient aircraft spare parts inventory management under demand uncertainty, Journal of Air Transport Management, Vol. 42, 101-109, doi:10.1016/ j.jairtraman.2014.09.006

[24] Do Rego, J. R.; de Mesquita, M. A. (2015). Demand forecasting and inventory control: A simulation study on automotive spare parts, International Journal of Production Economics, Vol. 161, 1-16, doi:10.1016/j.ijpe.2014.11.009

[25] Vaitkus, V.; Zylius, G.; Maskeliunas, R. (2014). Electrical spare parts demand forecasting, ELEKTRONIKA IR ELEKTROTECHNIKA, Vol. 20, No. 10, 7-10, doi:10.5755/j01.eee. $\underline{20.10 .8870}$

[26] Lengu, D.; Syntetos, A. A.; Babai, M. Z. (2014). Spare parts management: Linking distributional assumptions to demand classification, European Journal of Operational Research, Vol. 235, No. 3, 624-635, doi:10.1016/j.ejor.2013.12.043

[27] Barabadi, A.; Barabady, J.; Markeset, T. (2014). Application of reliability models with covariates in spare part prediction and optimization - A case study, Reliability Engineering \& System Safety, Vol. 123, 1-7, doi:10.1016/j.ress.2013.09.012

[28] Chen, M.-C.; Hsu, C.-M.; Chen, S.-W. (2006). Optimizing joint maintenance and stock provisioning policy for a multi-echelon spare part logistics network, Journal of the Chinese Institute of Industrial Engineers, Vol. 23, No. 4, 289-302, doi:10.1080/10170660609509325 
[29] Kennedy, W. J.; Wayne Patterson, J.; Fredendall, L. D. (2002). An overview of recent literature on spare parts inventories, International Journal of Production Economics, Vol. 76, No. 2, 201-215, doi:10.1016/S0925-5273(01)00174-8

[30] Ross, S. M. (2014). The Exponential Distribution and the Poisson Process (Chapter 5), Introduction to Probability Models, $11^{\text {th }}$ ed., Academic Press, Boston, 277-334 